\title{
Um olhar para a comunidade: experiência necessária para a formação do Terapeuta Ocupacional
}

\author{
Carla Patrícia Gameleira Rodrigues, Isabelle Fernandes Vieira Medeiros, \\ Lara Ranielly Sandes, Sandra Aiache Menta
}

\begin{abstract}
Resumo: Trata-se de um relato de uma experiência vivenciada por sete acadêmicos do estágio curricular supervisionado de Terapia Ocupacional em Saúde Coletiva, realizado na Vila Brejal, do bairro da Levada, na cidade de Maceió, no Estado de Alagoas. Tal experiência objetivou proporcionar aos acadêmicos um olhar sobre uma comunidade com base no território, nas instituições ali presentes e nas suas relações com as perspectivas de alterações na dinâmica do cotidiano das pessoas que participam de ações dessas instituições, em possíveis movimentos do processo do modo em que vivem. Além disso, propõe-se ainda perceber como a comunidade apresenta-se no contexto problemático situacional encontrado. Os aspectos metodológicos apontam para três momentos: vivência, acompanhamento de projetos e socialização em rodas de conversa. A vivência ocorreu através do contato com a Unidade Básica de Saúde do local, tendo os agentes comunitários de saúde como parceiros. O acompanhamento dos projetos foi realizado com a participação dos residentes de uma especialização multiprofissional em saúde da família, que ali desenvolvem ações das ONGs existentes nessa localização. A socialização ocorre nas rodas de conversas, nas quais o olhar dos acadêmicos quanto à situação de vulnerabilidade que se encontra essa comunidade possibilita vislumbrar a atuação da Terapia Ocupacional na área de saúde coletiva. Os resultados mostram que essa experiência possibilita aos acadêmicos adquirir capacidade de identificar a dinâmica da comunidade, reconhecer redes de suporte social e desenvolver habilidades para atuar no território.
\end{abstract}

Palavras-chave: Terapia Ocupacional, Terapia Ocupacional/Ensino, Saúde Coletiva, Desenvolvimento da Comunidade.

\section{A look to the community: necessary experience to the qualification of the occupational therapist}

\begin{abstract}
This text deals with the experience of seven students fromthe supervised curricular stage on Occupational Therapy in Collective Health, produced in "Vila Brejal - Levada" in Maceio, State of Alagoas. This experience aimed at providing students with a look into the community based on territory, institutions present in that neighborhood, and on their relationships with the alteration perspectives on the dynamics of the everyday lives of the people who participate in actions by these institutions. Besides, we propose a look into how the community presents itself before the challenging situational context found there. The methodological aspects aim at three movements: live experience, project follow up and socialization in conversation circles. The live experience occurred through a contact with the local Basic Health Unit, having health community agents as partners. The project follow up was possible with the participation of residents in a multi-professional family health specialization, which develops actions together with NGOs acting in the area. The socialization in conversation circles provided a window for thestudents to learn aboutthe vulnerable situation of the community, making it possible to visualize the action of occupational therapy in the collective health area. Results show that this experience enhances students' capacity of identifying the dynamics of a community, recognizing social support networks and developing abilities to act in the territory.
\end{abstract}

Keywords: Occupational Therapy, Occupational Therapy/Education, Public Health, Community Development.

Autor para correspondência: Sandra Aiache Menta, Universidade Estadual de Ciências da Saúde de Alagoas - UNCISAL, Rua Cônego de Lira, s/n, Trapiche da Barra, CEP 57010-374, Maceio, AL, Brasil, e-mail: sandramenta@ hotmail.com

Recebido em 19/10/2010; $1^{\text {a }}$ Revisão em 5/1/2011; 2 ${ }^{a}$ Revisão em 8/9/2011; Aceito em 10/10/2011. 


\section{Introdução}

A vivência na Comunidade Vila Brejal foi uma proposta do estágio em saúde coletiva do curso de Terapia Ocupacional da Universidade de Ciências da Saúde de Alagoas - UNCISAL, tendo este ocorrido no primeiro semestre de 2009. Seu objetivo foi conhecer a comunidade através de um olhar pautado na territorialização e assim permitir ao acadêmico visualizar a dinâmica da comunidade e, consequentemente, proporcionar um entendimento de intervenção terapêutica ocupacional em comunidade. O estágio em saúde coletiva é estruturado através de projetos temáticos, contexto no qual temas, como reconhecimento do território, identificaçáo da rede de suporte e dinâmica do cotidiano da comunidade são pautas constantes da formação dos acadêmicos. A escolha desse cenário, Vila Brejal, foi favorecida pela presença de uma equipe multiprofissional composta de residentes de saúde da família de uma pós-graduação da UNCISAL, que favorece um olhar mais ampliado de ações de uma equipe multiprofissional em uma comunidade. Vila Brejal é um território localizado às margens da Lagoa Mundaú, mais especificamente na região conhecida como Brejal, compreendendo parte do bairro da Levada, localizado próximo ao Mercado da Produção de Maceió-AL.

A prática baseia-se em princípios da Saúde Coletiva, tais como apontados por Carvalho e Ceccim (2006): propor formas diferenciadas de pensar e construir a formação profissional em articulação com os diversos campos que constituem as Ciências da Saúde, para que haja uma tomada de saberes e práticas que maximizem a mudança no contexto encontrado. Tal abordagem não fica restrita aos conhecimentos técnicos, pois vai além, nos impulsionando à construção de projetos de vida, sonhos pessoais e profissionais a partir $\mathrm{da}$ área de saúde. Nesse contexto, compreende-se a importância de uma formação de Terapeutas Ocupacionais habilitados para intervenção em Saúde Coletiva, levando-se principalmente em consideração a necessidade de profissionais preparados, através de construção, desconstrução e reconstrução de práticas coletivas.

A proposta foi realizada com uma carga horária de 200 horas, com a participação de sete acadêmicos. O acompanhamento da rotina de trabalho dos agentes comunitários de saúde da Unidade Básica de Saúde São Francisco de Assis, localizada na área de vivência, e dos residentes da especialização de saúde de família foi o principal veículo de interação, informação e comunicação com a comunidade ribeirinha. Os profissionais tinham como funçóes: mapear a área, identificar microáreas de risco, identificar e acompanhar ações de entidades governamentais e não governamentais locais, assim como também empreender um trabalho diário de contato direto com as famílias.

O grupo de acadêmicos composto de sete indivíduos foi subdividido em grupos menores, que tinham como metas: 1) reconhecer o território a partir de observação e acompanhamento de visitas às instituiçóes existentes, como escolas, associaçôes, igrejas e ONGs; 2) analisar a situação de moradia, infraestrutura, questôes ambientais, como saneamento e coleta de lixo; 3) analisar dados de violência para identificar a maneira como a comunidade lidava com o contexto; 4) observar as relaçôes familiares diante da situação do cotidiano das pessoas que ali vivem; 5) observar como os residentes da especialização de saúde da família e os agentes comunitários de saúde lidavam com toda a situação de vulnerabilidade da comunidade, considerada uma área de grande risco em relação à segurança pública e às questóes sociais e de saúde em Maceió.

Os momentos de socialização do processo de vivência eram semanais e ocorriam através de rodas de conversas na sede da UNCISAL.

Em comunidade, o estudante ou o profissional de saúde deve, por meio de um processo educativo, facilitar a construção de uma relação problematizadora no trabalho em saúde, constituindo espaço de produção e aplicação de saberes destinados ao desenvolvimento humano.

A comunidade é considerada em analogia à pessoa humana, sendo essencial para sua definição e para a apreensão de seus aspectos originais, e o seu reconhecimento. A relação pessoa-comunidade é essencialmente uma relação de interdependência constitutiva, na qual os aspectos ativos e passivos da pessoa e da comunidade são necessários no processo de tornarem-se si mesmas, algo somente possível a partir de uma abertura recíproca. (COELHO JÚNIOR; MAHFOUD, 2006). Nessa perspectiva, visualizamos e vivenciamos a importância da comunidade como agente modificador de sua realidade e conhecedor de suas necessidades. Percebendo como a comunidade possui as ferramentas necessárias para tal, precisando apenas de facilitadores para intermediar o processo de construção da organização social em relação à saúde, ao meio ambiente e aos direitos básicos, como segurança, educação e trabalho. A falta de segurança pode ser um dos maiores entraves na relação de aproximação e, consequentemente, de facilitação, que profissionais da saúde coletiva podem proporcionar para o uso das capacidades $\mathrm{da}$ comunidade local de movimentação para o processo de mudança situacional. 


\subsection{Bases para a compreensão do trabalho realizado}

A sociedade contemporânea, em seu estado de desenvolvimento, nos indica novas relaçóes com o saber, com as tecnologias e com o mundo, que apontam a necessidade de ressignificarmos as relaçôes entre as pessoas e repensarmos a produção de conhecimento (HALMANN et al., 2005).

O Brasil é um país marcado por profundas desigualdades sociais. Diante da parcela da população que se encontra em situaçáo de pobreza e de vulnerabilidade, inúmeros são os desafios no estabelecimento de políticas sociais que visam à melhoria da qualidade de vida das pessoas pertencentes a esses segmentos. Apesar de muitos avanços, uma questão que tem merecido a atenção dos teóricos e profissionais dessa área refere-se à caracterização e às especificidades das famílias em contexto de pobreza e exclusão. Mais importante do que delinear suas possíveis configuraçôes, é relevante investigar suas dinâmicas, funçóes, seus potenciais e estratégias de sobrevivência (CARDOSO; FÉRES-CARNEIRO, 2008).

Os dados resultantes da Pesquisa Nacional por Amostra de Domicílios (PNAD), do IBGE, de 1992 a 2004, mostram que Alagoas é o Estado mais pobre do Brasil, possuindo a menor renda real média e a maior proporção de pobres, e encontrando-se defasado tanto em termos de capital humano quanto de infraestrutura. Sua capital, Maceió, sofreu, num período de menos de dez anos, um acréscimo de $36 \%$ de sua população urbana, decorrente de um processo migratório advindo da zona rural, ocasionando a formaçáo de aglomerados populacionais desorganizados e possuidores de índices de desenvolvimento ainda mais alarmantes, como é o caso da Comunidade Vila Brejal (URANI, 2005).

$\mathrm{Na}$ comunidade, as condiçóes de vida daquela população surpreenderam a todos os acadêmicos, na medida em que se confrontaram com uma realidade bem adversa daquela que conheciam. No primeiro contato, foi feito um reconhecimento de microáreas por meio do qual foi possível visualizar as condiçôes ambientais, físicas e de higiene da comunidade. Observou-se que esta não possuía saneamento básico e algumas ruas não possuíam também asfaltamento, com córregos provenientes de esgotos a céu aberto e pocilgas, onde os porcos transitavam livremente nestas ruas, além de animais domésticos, em sua maioria doente.

Foram observadas ainda as disparidades de nível econômico, pois havia casas de bom aspecto, geralmente nas ruas asfaltadas, mas também havia locais onde as pessoas viviam em condiçóes subumanas, como casas com cerca de $1,70 \mathrm{~m}$ de altura e com piso de barro. A comunidade é repleta de vilas que adentram em corredores minúsculos e línguas negras (esgotos a céu aberto) "cortando as ruelas por todos os lados", além da pouca ou nenhuma higiene em algumas das localidades visitadas. Era insuportável o odor dos banheiros, muitas vezes por inadequada higienização, mas também por serem locais fechados e sem ventilação, causando por vezes mal-estar nos acadêmicos. Diversamente, os moradores que ali residiam pareciam estar acostumados, pois náo houve nenhuma manifestação verbal de indignação nem mesmo relato de queixas, como se a situação fosse de resignação e aceitação de uma condição que, aos nossos olhos, eram indignas para um ser humano, mas para os moradores algo de normalidade, sem questionamento de outras possibilidades pela comunidade local. Nas vilas visitadas, a maioria das casas tinha apenas um cômodo e, em algumas, se usavam tecidos velhos para separar quarto, sala e cozinha; os banheiros eram comunitários. O espaço era ainda dividido com animais doentes, com os quais as crianças brincavam em meio à sujeira.

Segundo relatos, há um grande fluxo de moradores, pois muitos vão passar apenas algumas noites nas casas das vilas, sem a menor preocupação com a higiene do local. Foi relatado ainda o caso de um morador que há algum tempo não voltava, mas quando frequentava o local ia apenas para dormir; e isto, em meio a lixo, ratos e baratas, sendo um incômodo para os vizinhos.

Nestas vilas, é cobrado semanalmente, em vez de mensalmente, o aluguel das casas; acreditamos ser assim devido à inadimplência dos moradores, que iam embora sem dar nenhuma explicação, muitas vezes fugindo da clandestinidade de trabalhos ligados ao tráfico de drogas ou dos envolvimentos em situação de crimes. Denotando ser uma característica marcante da Vila Brejal, há flutuação de moradores e as famílias estão em sua maioria em situação de vulnerabilidade.

Vale ressaltar que muitos momentos da vivência nessa comunidade foram acompanhados de tensão pelos acadêmicos, agentes comunitários de saúde e residentes, pois a aproximação de zonas de conflito em relaçáo às gangues, a policiais e traficantes, era constante. Ocorreu muitas vezes, dessa forma, a saída do grupo dos locais de forma brusca, quando nem mesmo a unidade de saúde permanecia aberta, apontando claramente a uma limitação do trabalho realizado pela UBS local.

As situações de constante violência compóem vários relatos de famílias, entendendo como 
um limitador de possibilidades em relação ao desenvolvimento escolar e social das crianças e dos adolescentes, pois vivem em insegurança, gerando a alternativa de algumas famílias enviarem seus filhos para viver com outros familiares em bairro próximos, porém com menos episódios de violência.

Assim, lares são transformados em cômodos e, consequentemente, há a desconstruçâo do cotidiano familiar.

Segundo Castel (1997), incontestavelmente a miséria econômica está na base da maior parte das situações de grande marginalidade, se não de todas. Afinal, são modos de vida que não encontram espaço nas sociedades dominadas pela preocupação com a organização racional e a rentabilidade econômica. A marginalidade constitui entáo um quarto mundo, povoado de estranhos estrangeiros, surgindo assim uma sociedade desfilada da própria sociedade.

A população residente nessa área é social e economicamente abaixo da média, e sua fonte principal de trabalho é informal, extraído do Mercado da Produção situado próximo à comunidade. Há também alto índice de criminalidade, principalmente relacionado ao tráfico de drogas, configurando assim um empecilho à permanência dessas pessoas nas localidades, seja por fatores econômicos ou de outra ordem.

Tais fatos denotam uma enorme fragilidade em seus suportes relacionais, já que estes também se encontram em risco, seja pela instabilidade da própria carência de recursos, seja pelo fato de acontecerem numa comunidade pouco assistida e amedrontada pela própria realidade, tornando-se um empecilho para serem eles, os moradores, os agentes modificadores de sua realidade. Durante a vivência, tentamos em vão formar um grupo de mulheres com o intuito de trocar saberes pautados em suas experiências e suas demandas, para que as mesmas pudessem provocar as mudanças que desejassem em suas realidades, mas esbarramos na dificuldade de se mobilizar a comunidade que desacredita as açôes, permanecendo no ciclo vicioso do assistencialismo.

A dimensão da cultura, como maneira de habitar um espaço e de partilhar dos valores comuns sobre a base de uma unidade de condição, representa outro elemento decisivo na constituiçáo da proteção aproximada. É o húmus nutritivo para a camada mais pobre da população, onde se partilham bens e serviços e constituem um sistema de trocas que mantém ou cria o laço social e o sentido. Estas redes de suporte possuem grande poder integrador" (BARROS; LOPES; GALHEIGO, 2002, p. 367).
Percebemos então quanto ainda é preciso para entender a dinâmica desta comunidade, que é tão peculiar e tão carente, pois as histórias de vida se misturam à história do território em questão, sendo necessário ainda investir na identificação do público sem o dicotomizar da comunidade.

Como salienta Ribeiro, apud Cardoso e FéresCarneiro (2008), há um consenso sobre a necessidade e a relevância de identificar suficientemente a comunidade, para assim alcançar a integralidade do cuidado, aspecto que deve ser contemplado na elaboração de programas sociais e estratégias de assistência, para a prestaçáo de serviços de qualidade.

A fim de buscar uma melhor identificação, foram visitados lideranças sociais e projetos de apoio à comunidade, como o Erê, Projeto Brejal - Visão Mundial e a Associação das Mulheres.

O Projeto Alternativo de Apoio a Meninos e Meninas de Rua da Organização Não Governamental - Erê, patrocinado pela Comunidade Evangélica de Halstenbek e pela Fundação Walter Breitenstein de Kiel - Alemanha, destina-se a resgatar a cidadania e reintegrar meninos e meninas de rua à sociedade e à família através de açóes e atividades socioeducativas/ culturais. No período em que vivenciamos essa comunidade, o projeto funcionava como uma escola para filhos de famílias que estavam sendo assistidas pela mesma, em outro prédio, em decorrência da dependência química.

O Projeto Brejal é patrocinado pela Visão Mundial, a qual tem diretrizes que apresenta uma variedade de ações que o mesmo pode consagrar na comunidade; dentre estas, estão capoeira, palestras educativas e leituras. Enquanto estávamos na comunidade, o referido projeto estava desativado, pois o prédio estava interditado pelas péssimas condiçôes físicas sanitárias em razão das chuvas e da falta de escoamento de água.

A Associação de Mulheres da Vila Brejal é uma sociedade civil, autônoma, sem fins lucrativos, com foro e sede administrativa no bairro Bom Parto, na cidade de Maceió, Alagoas. Atuando na Vila Brejal, é composto, conforme Estatuto, pela presidenta, vice-presidenta, secretária, vice-secretária, tesoureira e vice-tesoureira. Apresenta como objetivos: organizar as mulheres na luta pelos seus direitos; contribuir no processo de conscientização das mulheres, através de açóes educativas; promover a capacitaçáo de mão-de-obra através dos grupos de geraçóes de renda; orientar as mulheres a respeito de sua saúde, planejamento familiar e educação de seus filhos. As reuniôes acontecem mensalmente, porém estas se encontravam suspensas devido ao comprometimento estrutural do Centro e pela falta 
de parcerias e, consequentemente, de verba para reforma. O Centro disponibiliza seu espaço para programas paralelos (aulas de violino e futebol), os quais contribuem no pagamento de despesas tais como água e energia elétrica.

Segundo Campos (2001), a contextualização territorial é importante para o desenvolvimento do trabalho, pois permite que o processo proposto pela Terapia Ocupacional possa ser ampliado para a construção de novas abordagens, para a utilização de novos espaços, para as dimensôes macroestruturais, correlacionando aspectos que na prática não se isolam, mas sáo permeados uns pelo outros.

Nessa direção, a saúde coletiva provoca um debate sobre a construção de uma "clínica ampliada", a busca do protagonismo do sujeito e não apenas da doença do território em que está inserido, ampliando o setting terapêutico, em prol de uma clinica do sujeito. Ao realizarmos esse reconhecimento do território e da cultura da comunidade, foi entáo possível atingir um diagnóstico da mesma, verificando-se a existência de uma dificuldade de mobilização social. As ONGs citadas, apesar de terem intervençóes específicas, como ditas anteriormente, nos relataram dificuldades em mobilizar as pessoas para discussóes acerca de saúde e cidadania; por exemplo, caso não houvesse um ganho extra como cesta básica, não ocorreria uma participação significativa dos indivíduos em espaços de discussáo. Outro fator importante de dificuldade citado pelas ONGs é o fato de as atividades não contarem com financiamento ou apoio governamental, dificultando a continuidade das açôes e dos projetos.

Ainda sobre tal observação, em uma reunião de que o grupo participou, na casa paroquial ao lado da Igreja São Francisco de Assis, promovida pelos profissionais da residência multiprofissional em saúde da família que visava levantar e provocar problematização do contexto relatado pelos próprios moradores, foi constatada pouca participação da comunidade e, nesse aspecto, nos indagamos e refletimos sobre a cultura dessa população, que não se apropria de conhecimentos de direitos e cidadania, ficando condicionada ao imediatismo do assistencialismo ou talvez os moradores não acreditem na possibilidade de uma mudança real feita pela própria comunidade. Isso nos remete a uma reflexão ainda mais profunda sobre o processo de alienação provocado pelo próprio sistema.

"O resultado de um sistema fundamentado nas relaçóes do capital, no qual sua geração e manutenção consistem na exploração, exclusão e alienação de povos em prol do desenvolvimento "global", tem se configurado como eixo central das problemáticas atualmente encontradas nas relaçôes sociais, ocasionando a opressão de classes que constituem a base populacional. Homens e Mulheres que, impedidos do acesso ao desenvolvimento tecnológico, cultural e histórico, vivenciam uma realidade desumana e desumanizante [...] (SAGGIOMO, 2005, p. 143).

O estágio teve como resultado o apropriamento de um olhar diferenciado enquanto profissionais de saúde preparados para atuar na saúde coletiva, porém nos coube apenas iniciar uma proposta nova de estágio e não chegamos a realizar nenhuma intervenção concreta, ficando para o próximo grupo de estágio dar continuidade à dinâmica já iniciada. Porém, o mesmo náo ocorreu devido à mudança do cenário do estágio curricular para outra área que proporcionasse mais segurança para os estagiários e o supervisor.

Segundo Mângia, Almeida e Lancman (2005), no editorial sobre "A formação dos Terapeutas Ocupacionais e os processos de mudanças nas graduaçôes em saúde", há algum tempo se discute sobre a necessidade de redefinir as diretrizes curriculares da Terapia Ocupacional atreladas ao sistema de saúde existente, visando o trabalho em equipe e a atenção integral à saúde. Sugere-se uma discussão mais aprofundada sobre a relação da profissão com as políticas públicas, promovendo sistematização e visibilidade de experiências de ensino que mostrem os benefícios tanto para os profissionais como para os usuários do SUS.

Tendo em vista a abrangência das açóes em saúde nesse contexto, faz-se necessário abrir-se para um diálogo com disciplinas, desenvolvendo estudos teóricos e práticos sobre as atividades em Terapia Ocupacional, para atuarmos como instrumento de autovalorização e de produção de sentido pessoal. Ampliar os espaços e promover a emancipação pessoal e social em projetos individualizados, mas sempre contextualizados em melhoria de qualidade de vida. Atuar, então, sempre deslindando processos sociais mediatamente implicados na desfiliação - em vez de exclusão, preparando, a nosso ver, o Terapeuta Ocupacional para atuar nesse campo compreendendo suas nuanças fundamentais (BARROS; LOPES; GALHEIGO, 2002).

\section{Considerações finais}

A vivência na comunidade da Vila Brejal proporcionou aos acadêmicos uma sensibilização imprescindível para a formação de Terapeutas Ocupacionais capazes de atuar no território, em 
espaços comunitários e em instituiçôes sociais, capacitando-os para, a partir da demanda da população, contribuir para o equacionamento de suas necessidades e para uma escuta e uma intervenção que se construa com o outro em seu contexto e sua história (BARROS; LOPES; GALHEIGO, 2002).

$\mathrm{O}$ olhar que, a princípio, enxergava somente a vulnerabilidade passou a visualizar também a importância de identificar a dinâmica da comunidade e propor uma intervenção que se construa em rede, articulando-se de forma a enraizar-se na própria história do território que será assistido, formando, então, um conhecimento pautado no saber comunitário e não somente no tecnicismo científico, pois não há como intervir em comunidade sem se aproximar da mesma.

Outro ponto importante vivenciado e apreendido neste relato de experiências pelos acadêmicos foi a condicionalidade de que, ao perceber o outro como sujeito, como coletivo, como família singular, nem todas as técnicas apreendidas na formação do Terapeuta Ocupacional são suficientes para dar conta das habilidades necessárias de atuação na comunidade, pois o como "fazer terapia ocupacional na comunidade" tem que ser antecedida do conhecimento da comunidade em sua dinâmica de vida, construção de saberes, desconstrução de saberes, quebra de conceitos pré-estabelecidos e busca por conceitos novos e adequados para a realidade dinâmica de uma comunidade.

No início de um processo de construção de sonhos coletivos e técnicas de construçôes de projetos comunitários, é primordial internalizar que o sujeito é o ator de sua história e o Terapeuta Ocupacional é o elo de uma necessidade que perpassa pela área da saúde e social, necessitando da prática da interdisciplinaridade, com a certeza de que esta deve ser contínua. Somando-se à necessidade de açôes intersetoriais permanentes entre governo, sociedade organizada, profissionais e a universidade, com acadêmicos comprometidos e, acima de tudo, crédulos de que o processo de uma mudança de modos de pensar e agir de uma determinada comunidade é possível, desde que o olhar seja desnudo de conceitos pré-estabelecidos.

Vale ressaltar que os momentos de reflexão da realidade apreendida dessa comunidade aconteceram durante quatro meses através de rodas de conversas (socialização), mas que permanecem ainda em cada acadêmico muito mais do que uma experiência na formação profissional, pois hoje faz parte da formação de cada um como pessoas que acreditam em sujeitos de direito e em mudanças possíveis e, acima de tudo, necessárias para a busca de uma sociedade com menos desigualdades sociais e, consequentemente, mais justa.

\section{Referências}

BARROS, D. D.; LOPES, R. E.; GALHIEIGO, S. M. Projeto Metuia - Terapia Ocupacional no Campo Social. O Mundo da saúde - São Paulo, ano 26, v. 26, n. 3, p. 365-369, 2002.

CAMPOS, R. O. Clínica: a palavra negada - sobre as práticas clínicas nos serviços substitutivos de Saúde Mental. Saúde Debate, v. 25, n. 58, p. 98-111, 2001.

CARDOSO, C. L.; FÉRES-CARNEIRO, T. Sobre a família: com a palavra, a comunidade. Estudos e Pesquisas em Psicologia, v. 8 n. 2, 2008.

CARVALHO, Y.M.;CECCIM,R.B. Formação e educação em saúde: aprendizados com a Saúde Coletiva. In: CAMPOS,G.W.S.; MINAYO, M. C. S.; AKERMAN, M.; DRUMOND JÚNIOR, M.; CARVALHO, Y. M. (Orgs.). Tratado de Saúde Coletiva. São Paulo: HUCITEC, 2006. p.149-182.

CASTEL, R. A dinâmica dos processos de marginalização: da vulnerabilidade à "desfiliação". Caderno $C R H$, v. 26-27, p. 19-40, 1997.

COELHO JÚNIOR, A. G.; MAHFOUD, M. A relação pessoa-comunidade na obra de Edith Stein. Memorandum, v. 11, p. 08-27, 2006.

HALMANN, A. Z.; BONILLA, M. H.; MARTINS, É C.; PEREIRA, G. S.; OLIVEIRA, H. L.; COSTA, H. M.; SILVA, L. B.; SANTOS, P. M. B.; CASTRO, T. C. E. S.; BARRETO, U.; SILVA, V. Construção Coletiva do Saber: uma vivência na FACED/UFBA . Diálogo Cientifico, 2005. Disponível em: <http://www. cinform.ufba.br/vi_anais/docs/AdrianeHalmann. pdf>. Acesso em: 18 nov. 2009.

MÂNGIA, E. F.; ALMEIDA, M. C.; LANCMAN, S. A formação dos Terapeutas Ocupacionais e os processos de mudança nas graduaçóes em saúde. Revista de Terapia Ocupacional da Universidade de São Paulo, v. 16, n. 3, p. i-ii, 2005.

NASCIMENTO, M. V.; GOMES, S. R. S.; FERRAZ, C. V.; GONÇALVES, L. B. Democratização da Informação e Inclusão Social: estudo de caso com a ong - ERÊ. In: REUNIĀO ANUAL DA SOCIEDADE BRASILEIRA PARA O PROGRESSO DA CIÊNCIA - SBPC, 60., 2008, Campinas. Anais... Campinas: UNICAMP, 2008. Disponível em: <http://www. sbpcnet.org.br/livro/60ra/resumos/resumos/R1985-1. html>. Acesso em: 18 nov. 2009.

PIMENTEL, J. B. Levada. O JORNAL, Maceió, 04 ago. 1996. Disponível em: <http://www.bairrosdemaceio.net/site/index. php?Canal=Bairros\&Id=27>. Acesso em: 18 nov. 2009.

SAGGIOMO, T. G.; SILVA, A. L.; MENDES, A. M. C.; KUNDE, C. F.; OLIVEIRA, C.; VITOLA, C.; NASCIMENTO, F. S.; FRANCO, J. B.; GARCIA, N. M.; PETRY, R.; LEME, R. R.; COSTA, T. 
G. et al. Projeto Agente Jovem de Desenvolvimento Social e Humano: assistencialismo ou formação de lideranças na comunidade. CEAMECIM, 2005. 143 p. Disponóvel em: <www.ceamecim.furg.br/-tusnski/ paginas/paulofreire/inscricoes/FILES/p143.doc>. Acesso em: 18 nov. 2009.
URANI, A. Um diagnóstico socioeconômico do Estado de Alagoas a partir de uma leitura dos dados da Pesquisa Nacional por Amostra de Domicílios do IBGE (19922004). IETS, 2005. Disponível em: <http://www.iets. org.br/biblioteca/Um_diagnostico_socioeconomico_ do_Estado_de_Alagoas.pdf $>$. Acesso em: 18 nov. 2009.

\section{Autores}

\section{Carla Patrícia Gameleira Rodrigues, Isabelle Fernandes Vieira Medeiros, Lara Ranielly Sandes}

Acadêmicas do quinto ano de Terapia Ocupacional da Universidade Estadual de Ciências da Saúde de Alagoas - UNCISAL, Maceió, AL, Brasil

\section{Sandra Aiache Menta}

Mestre em Psicologia pela Universidade Católica Dom Bosco - UCDB, Especialista em Saúde Pública - Escola Nacional de Saúde Pública Sergio Arouca - ENSP/FIOCRUZ, Supervisora do estágio de Saúde Coletiva de Terapia Ocupacional da Universidade Estadual de Ciências da Saúde de Alagoas - UNCISAL, Maceió, AL, Brasil

\section{Contribuição dos Autores}

O manuscrito foi uma construção para a avaliação formativa dos acadêmicos no processo de aprendizagem para o estágio, projeto concebido no tema principal, correlação dos conceitos e estruturado texto, pela professora e supervisora de estágio, Sandra Aiache Menta. A Pesquisa bibliográfica foi de responsabilidade das acadêmicas, Carla Patrícia Gameleira Rodrigues, Isabelle Fernandes Vieira Medeiros e Lara Ranielly Sandes. A redação do texto inicial foi elaborado pelas acadêmicas, Carla Patrícia Gameleira Rodrigues, Isabelle Fernandes Vieira Medeiros e Lara Ranielly Sandes. A revisão da redação inicial, a redação final, a revisão e resumo, foram realizados pela professora supervisora Sandra Aiache Menta. 
